\title{
Larva de quinto estádio e pupa de Caligo martia (Godart) (Lepidoptera, Nymphalidae, Brassolinae) ${ }^{1}$
}

\author{
Mirna M. Casagrande ${ }^{2}$ \\ Olaf H.H. Mielke ${ }^{2}$
}

\begin{abstract}
Fifth larval instar and pupa of Caligo martia (Godart) (Lepidoptera, Nymphalidae, Brassolinae). Description of the fifth larval instar and pupa of Caligo martia (Godart, [1824]) from material reared in southern Brasil are described and illustrated. The larvae feed on two species of Cyperaceae. The caterpillar and pupa appearences are compared with others Caligo species.

KEY WORDS. Nymphalidae, Brassolinae, Caligo martia, immature stages, hostplant
\end{abstract}

As espécies do gênero Caligo Hübner, [1819], têm tamanho avantajado, sendo que nenhuma delas possui menos que 10 centímetros de envergadura, portanto, as larvas são de grande porte e possuem na sua grande maioria hábitos gregários. Entre as espécies conhecidas para o sul do Brasil, apenas duas delas, Caligo martia (Godart, [1824]) e Caligo arisbe Hübner [1822] voam durante os horários de sol intenso, enquanto que as outras nos crepúsculos matutino e vespertino.

Neste trabalho descreve-se e ilustra-se a larva de quinto estádio e a pupa e, ilustra-se o adulto de Caligo martia provenientes de Rio Natal, São Bento do Sul, Santa Catarina, Brasil. A nomenclatura das áreas do corpo da larva estão descritas conforme definidas em PETERSON (1962) e da pupa como em CASAGRANDE (1979).

Larva de quinto estádio (Figs 1-3)

Cabeça. Coloração geral bege com pontos e faixas castanho-escuro com cerdas bege. Na região posterior com quatro pares de escolos: dorsais, látero-dorsais, laterais e látero-ventrais, diminuindo aproximadamente a metade em tamanho, em direção à face ventral.

Faixa branco-amarelada desde a base da mandíbula acompanhando a sutura epicranial, divergindo próxima ao vértice e se prolongando até o ápice dos escolos dorsais. Desta faixa, em direção látero-ventral, até o escolo látero-dorsal, duas estrias castanho-escuro intercaladas por área castanho-claro. Lateralmente, desde o escolo látero-dorsal até o início da base da cabeça a coloração é branco-amarelada. Regiões ventral e posterior da cabeça castanho-escuras.

Mandíbula lisa de coloração bege na base e castanho-escuro no restante de sua extenção. Látero-ventralmente de aspecto corrugado e de coloração avermelhada com cerdas bege.

1) Contribuição número 1181 do Departamento de Zoologia, Universidade Federal do Paraná

2) Departamento de Zoologia, Universidade Federal do Paraná. Caixa Postal 19020, 81531-990 Curitiba, Paraná, Brasil. Bolsista do CNPq. 
Corpo pubescente de coloração geral palha com várias faixas e estrias em diferentes tons de castanho e verde escuro. As cerdas são simples, castanho-claro, sobre pináculos translúcidos. No tórax, área dorsal enegrecida, dividida longitudinalmente por linha castanho-clara. Esta linha, nos segmentos abdominais totalmente preta, continua-se pela área dorsal do corpo e termina entre a base dos prolongamentos caudais, levemente mais estreita que no meio do corpo e similar à aquela apresentada pelas larvas de quinto instar de Caligo illioneus illioneus (Cramer, [1776]). Na área dorsal dos segmentos abdominais três a sete projeções tegumentares alaranjadas, sendo a do quarto segmento o dobro em tamanho que as outras. Estas mesmas estruturas são observadas em Caligo illioneus illioneus (Cramer, [1776]), Caligo beltrao (Illiger, 1801), Caligo brasiliensis (C. Felder, 1862) e Caligo eurilochus eurilochus (Cramer, [1775]).

Área supraespiracular, mais escura que o restante do tegumento, marcada tanto dorsal como ventralmente por linha mais clara. Após o primeiro segmento abdominal, a cor escura desta área difunde-se em linhas, menos evidentes, tanto longitudinais como obliquas à linha média do corpo. Área espiracular de coloração palha, igual ao restante do tegumento. O limite inferior da área espiracular define nitidamente a separação entre as regiões dorsal e ventral do corpo, esta de coloração castanho-escuro.

Pernas torácicas de coloração castanho-avemelhada e falsas pernas abdominais mais claras, com planta apresentando ganchos distribuídos em mesal penelipse, triordinal e uniserial, iguais à aqueles descritos por CASAGRANDE (1979) para Caligo beltrao (Illiger, 1801).

Projeções da placa anal alaranjadas, com cerdas mais escuras.

As larvas atingem neste último estádio o comprimento máximo de $11 \mathrm{~cm}$, incluindo a cabeça e as projeções da placa anal.

Planta hospedeira. As larvas alimentam-se de folhas de Pleurostachys puberula Boeck e Carex brasiliensis St. Hil., Cyperaceae.

\section{Pupa (Figs 4-6)}

Aspecto geral marmóreo entre tons de castanho-claro a escuro com mesclas em tons de verde oliva, rosa e branco. Vários pontos e áreas enegrecidas estão distribuídas em todas as regiões do corpo. Este aspecto é semelhante ao que pode-se observar na face ventral das asas dos adultos.

O tórax, incluindo as protuberantes tecas alares, é pouco mais alaranjado e nitidamente delimitado por linha escura. Lateralmente, próximo ao meio das tecas alares, duas manchas triangulares e espelhadas como aquelas citadas por CASAGRANDE (1979) para Caligo beltrao (Illiger, 1801).

Várias cerdas estão distribuídas por todo o corpo, sendo algumas maiores e mais escuras na linha média dorsal, no vértice e próximo aos olhos. Estas mesmas cerdas também foram observadas por MALO \& WILLIs (1961) em Caligo eurilochus (Cramer, [1775]).

Figs 1-6. Caligo martia. (1-3) Larva de quinto estádio: (1) vista dorsal, (2) vista lateral, (3) detalhes da cabeça e segmentos torácicos; (4-6) pupa: (4) vista ventral, (5) vista lateral, (6) vista dorsal. 

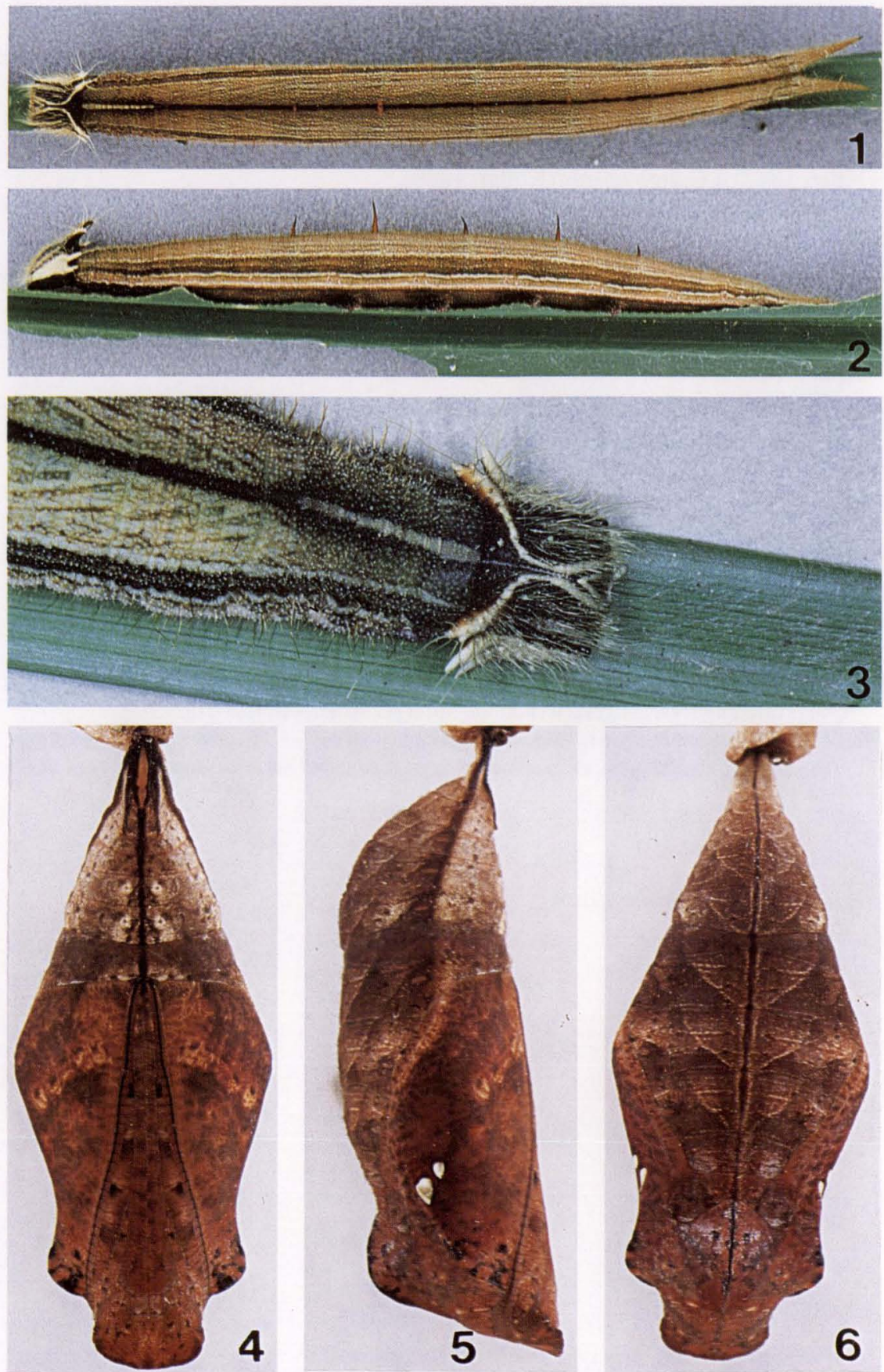

Revta bras. Zool. 17 (1): 75 - 79, 2000 
Os segmentos abdominais são destacados pelo branco de aspecto aveludado, principalmente na face ventral, mesclado com fina pontuação castanho-escuro. $\mathrm{Na}$ face dorsal, linhas oblíquas, mais escuras, percorrem os segmentos abdominais desde a linha média até as laterais sobre os espiráculos, estas linhas também são citadas por Young \& MUYSHONDT (1985) para Caligo memnon (C. Felder \& R. Felder, 1867) e Caligo atreus (Kollar, 1850).

O comprimento das pupas variou entre 4,0 e $4,5 \mathrm{~cm}$ e a largura entre 1,8 e 2 $\mathrm{cm}$.

Este estágio tem uma duração média de 30 dias, com as larvas de quinto estádio empupando em meados de novembro e os adultos (Figs 7-10) emergindo em meados de dezembro, sendo a espécie univoltina.

AGRADECIMENTO. Ao Prof. Dr. Armando Cervi do Departamento de Botânica da Universidade Federal do Paraná pela identificação das plantas hospedeiras.

\section{REFERÊNCIAS BIBLIOGRÁFICAS}

Casagrande, M.M. 1979. Sobre Caligo beltrao (Illiger). I: Taxonomia, Biologia, Morfologia das Fases Imaturas e Distribuições Espacial e Temporal (Lepidoptera, Satyridae, Brassolinae). Rev. Brasil. Biol., Rio de Janeiro, 39 (1):173-193.

MALO, F.\& E.R. WILLIS. 1961. Life history and biological control of Caligo eurilochus, a pest of banana. Jour. Econ. Ent. 54: 530-536.

Peterson, A. 1962. Larvae of Insects. An Introduction to Neartic Species. Part. I Lepidoptera and Plant Infesting Hymenoptera. Ann Arbor, Michigan, Edwards Brothers, Inc., 315p.

Young, A.M. \& A. MuyshondT. 1985. Notes on Caligo memnon Felder and Caligo atreus Kollar. (Lepidoptera: Nymphalidae: Brassolinae) in Costa Rica and El Salvador. Jour. Res. Lep. 24 (2): 154-175.

Recabido em 29.X.1998; aceito em 03.11.2000.

Figs 7-10. Caligo martia. (7-8) Macho: (7) vista dorsal, (8) vista ventral; (9-10) fêmea: (9) vista dorsal, (10) vista ventral. 

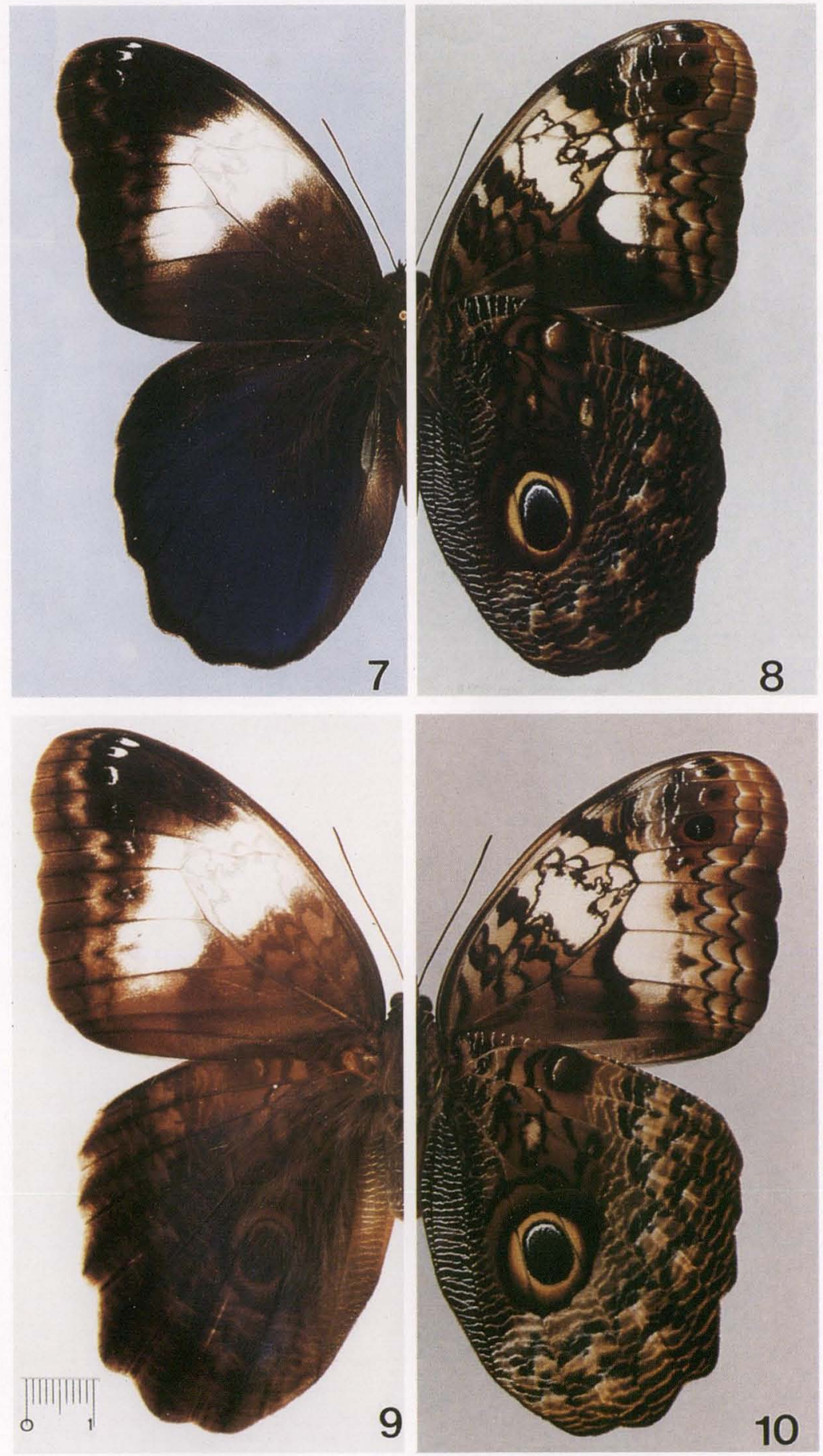

Revta bras. Zool. 17 (1): 75 - 79, 2000 